\title{
EDUCAÇÃO CLANDESTINA NO GUETO DE VARSÓVIA: CANTINAS-ESCOLA COMO ESPAÇO DE RESISTÊNCIA
}

Nanci N. Souza*

\section{Resumo}

Esta comunicação apresenta alguns resultados da pesquisa de mestrado a respeito da educação enquanto forma de resistência. O objeto deste estudo é o ensino elementar clandestino, posto em prática pelos educadores logo após o fechamento do gueto de Varsóvia, época em que as crianças e jovens vivenciavam situações extremas de intolerância. A partir de registros de época, procurou-se conhecer as estratégias direcionadas para preservar os judeus como povo, visto que esses estavam condenados ao extermínio pelos nazistas. Constatou-se que a educação, em distintos momentos e espaços clandestinos, serviu para garantir o mínimo de dignidade, fosse física ou cultural, aos judeus excluídos pelos nazistas como "raça inferior". Como espaço de resistência, tem-se como exemplo as cantinas-escola da Rua Karmelicka ${ }^{\circ}$ 29, da Rua Krochmalna $n^{\circ} 36$ e da Rua Nowolipki $n^{\circ}$ 68, nas quais foram implementadas o Programa dos Cursos Clandestinos sob a tutela da instituição de ensino TsYShO. A relevância deste estudo está em analisar a ação daqueles que se encontravam degradados da condição humana, que buscavam, por meio da educação clandestina, fazer frente aos conceitos nazistas, preservando sua dignidade e defendendo sua própria ideologia, vinculada a sua sobrevivência e a sua continuidade como indivíduos e como povo.

Palavras-chave: Clandestinidade; dezumanização; educação; gueto; resistência.

\begin{abstract}
This paper presents some results of the master's research about education as a form of resistance. The object of this study is the elementary education clandestine implemented by educators immediately after the closing of the Warsaw Ghetto, a time when children and young people were experiencing extreme intolerance. The records from the time, sought to know the strategies aimed to preserve the Jews as a people, as these were doomed to

\footnotetext{
* Mestre em Letras pelo Programa Língua Hebraica, Literatura e Cultura Judaicas (FFLCH), da Universidade de São Paulo (USP). Pesquisadora do Laboratório de Estudos de Etnografia, Racismo e Discriminação (LEER) e do Arquivo Virtual sobre Holocausto e Antissemitismo (ARQSHOAH).nancyead@yahoo.com.br
} 
extermination by the Nazis. It was found that education, at different times and spaces underground, served to ensure a minimum of dignity, be physical or cultural, excluded Jews by the Nazis as "inferior race". As a space of resistance, we have the example of canteens school 29, Karmelicka, st, 36, Krochmalna, st and 68, Nowolipki st, which were implemented in the Course Program Clandestine under the tutelage of the institution TsYShO teaching. The relevance of this study is to analyze the action of those who were degraded of the human condition, who sought, through education clandestine confront the Nazi concepts, preserving dignity and defending their own ideology, linked to their survival and continuity as individuals and as a people.

Keywords: Underground; dehumanization; education; ghetto; resistance.

\section{Introdução}

A documentação citada neste artigo faz parte do Arquivo Ringelblum, também conhecido como Arquivos do Gueto de Varsóvia, que se encontra atualmente sobre a custódia do Instituto de História Judaica de Varsóvia. Refere-se à educação clandestina desenvolvida no gueto de Varsóvia para crianças do ensino elementar, cuja idade era inferior aos quinze anos.

A documentação aborda o trabalho educacional patrocinado pela Tsentrale Yidische Shul Organizatsie (TsYShO) - [Organização ou União Central das Escolas Judaicas], em escolas que funcionavam em refeitórios chamadas cantinas-escola. Refere-se aos Objetivos e Métodos de trabalho para os cursos ministrados em três cantinas-escola, nomeado: Programa dos Cursos Clandestinos sob a tutela da TsYShO implementados nas cantinas-escola da Rua Karmelicka $n^{\circ} 29$, da Rua Krochmalna $n^{\circ} 36$ e da Rua Nowolipki $n^{\circ} 68$.

O registro desse material é resultado da resistência posta em prática no gueto de Varsóvia. A manifestação cultural clandestina permitiu o acesso a inúmeros diários escritos durante o holocausto. Alguns escreveram como meio de resguardar a si mesmo e sua história, outros para denunciar as tragédias vividas pelos judeus na Europa depois da ocupação nazista; e outros talvez, para refletir por meio das letras suas angústias e esperanças.

A cada passo dado entre a trama nazista que instituía nos países conquistados seu reinado de terror e o dia-dia dos judeus nesse gueto, é possível evidenciar o esforço sobrehumano de seus habitantes no âmbito sociopolítico, cultural e educacional. A história do 
gueto de Varsóvia não se limitou a uma crônica de tragédia, mais que isso, ela trouxe dos escombros da guerra o testemunho daqueles que viveram, morreram e sobreviveram a esse gueto.

\section{A invasão da Polônia pela Alemanha nazista}

Após a invasão da Polônia, em setembro de 1939, os judeus poloneses passaram a sofrer restrições no âmbito religioso, cultural e educacional, e os que transgredissem tais restrições estavam sujeitos à pena de morte. A Alemanha nazista negava aos judeus o direito à vida, à humanidade.

Quando os nazistas bombardearam Varsóvia, destruíram instalações escolares levando a maior parte das escolas para crianças judias a deixarem de funcionar. De acordo com o artigo de Suzan Kardos (2002, p. 37) intitulado "Not Bread alone: clandestine Schooling and resistance in the Warsaw ghetto during the holocaust", embora os nazistas tenham proibido a escolarização para os judeus, algumas escolas permaneceram ativas por alguns meses até que o último edifício na Rua Okopowa, 55 fosse tomado pelos nazistas.

Helena Gutman-Staszewska, sobrevivente da guerra, escreveu em seu diário "que todos os professores foram despedidos em $1^{\circ}$ de dezembro de 1939, cerca de uns 400 professores das escolas primárias judaicas. Com esta medida, cerca de 30.000 crianças ficaram sem estudar e sem ter acesso a escola”. (GRYNBERG, 2004, p. 435).

Desde o início da ocupação, o Judenrat ${ }^{1}$ solicitava continuamente às autoridades alemãs permissão para reabrir as escolas para crianças judias. Com exceção de alguns cursos técnicos autorizados pelos nazistas, a solicitação da liderança judaica se mostrou infrutífera. Em 11 de outubro de 1940, Adam Czerniakow, líder do Judenrat do gueto de Varsóvia escreveu em seu diário: "Tem havido rumores de que, por medo de epidemias, as escolas judaicas permanecerão fechadas". (KARDOS, 2002, p. 37).

As restrições da ocupação alemã no domínio educativo e cultural atingiram particularmente as crianças. Conforme Ruta Sakowska (2007, p. 18), as escolas para alunos judeus de Varsóvia, inclusive as escolas primárias, foram fechadas em dezembro de 1939. A partir de 1940, o processo de interdição tomou proporção ainda maior: fecharam as casas de rezas; as livrarias judaicas e lojas de artigos religiosos. Os judeus foram proibidos de frequentar bibliotecas públicas e suas bibliotecas impedidas de funcionar. Todos esses "nãos" nazistas privavam os judeus dos Direitos do Homem.

\footnotetext{
${ }^{1}$ Judenrat (em alemão, Conselho Judeu). RINGELBLUM, 2003, p. 485.
} 
Levi (1988, p. 25), sobrevivente de Auschwitz escreve que "o homem privado de tudo que possui, será um ser vazio, reduzido a puro sofrimento e carência, esquecido de dignidade e discernimento, pois quem perde tudo, pode chegar a perder a si mesmo. O homem nessa situação corre o risco de perder sua própria condição humana”.

Esgotados pela fome, privados de direitos, de um lar, e em muitos casos, de seus familiares, os judeus tem outro desafio pela frente: a substituição da cerca em torno da área de quarentena, local onde se encontrava o bairro judeu de Varsóvia, por um muro.

O processo de desumanização estava em curso de forma bem avançada, e a fome era a protagonista desse processo que, já no início de janeiro de 1940, levava a óbito diariamente entre 50 a 70 judeus. Muitos deportados morreram depois de chegarem a Varsóvia como resultado das terríveis condições do translado. Ringelblum denuncia em março de 1940 a morte de 200 crianças em um orfanato de Varsóvia. A fome investia no esgotamento da humanidade dos homens e desafiava sua capacidade de resistir.

\section{Origens da educação clandestina}

Em novembro de 1940, quando o bairro judaico de Varsóvia foi transformado em gueto, os nazistas continuaram a proibir os judeus de operarem escolas para as aproximadamente 30 a 40 mil crianças em idade escolar que lá estavam confinadas. Apesar dessas proibições, diversas atividades educacionais clandestinas estavam sendo promovidas, como: jardins de infância e "cantinhos das crianças"; salas de aulas para o ensino elementar funcionando em conjunto com as cantinas públicas; uma ativa rede de grupo de estudo prosperou; a educação religiosa persistiu; e, de todas as maneiras possíveis, grupos de jovens continuaram com suas atividades políticas e intelectuais como antes da guerra; aulas particulares aconteciam; algumas escolas de ensino médio clandestinas, e centenas de círculos de estudos também existiram. O treinamento vocacional e programas de nível universitário também foram oferecidos.

Havia também professores, como Jaim Kaplan que ensinava a grupos juvenis, às vezes preparando-os para os exames escolares estatais poloneses, demonstrando, assim, que a educação desses jovens estava orientada não apenas para o presente, mas também para um futuro com possibilidades.

De acordo com Kardos (2002, p. 43), logo após a formação do gueto os professores judeus começaram a formar grupos clandestinos de estudos, tanto pela necessidade de ganhar dinheiro como para ajudar aqueles que tinham necessidade de escolas, desde que um grande 
número da juventude judaica em todos os níveis estava sendo privados de uma educação. No ensaio do grupo Oneg Schabat ${ }^{2}$, "Estudo Preliminar em Ensinar Pessoas Durante a Guerra", o autor reportou que no gueto "os jovens estudavam diligentemente e na maior parte do tempo monstravam interesse maior na medida em que faziam o seu trabalho" e "os professores trabalhavam duramente e com excepcional honestidade, embora sua situação material fosse extremamente difícil".

Essa atividade, a principio motivada economicamente, foi mais tarde motivada por outras razões também. A sobrevivente Vladka Meed (2000 apud KARDOS, 2002, p. 44) relembra:

As pessoas continuavam nas difíceis situações e segurando-se a vida como seres humanos [...] nossa vizinha [...] no gueto estava vendendo pedaço de pão [...] fora do edifício de nossa casa [...] e prestando atenção para ver se uma patrulha alemã não estava passando, porque em seu apartamento, acima do nosso, sua filha estava dando aulas para as crianças [...] uma pequena escola ilegal. Esta mulher nem pensava que era uma heróina, nem sua filha, mas elas estavam conduzindo classes ilegais para crianças, sabendo que se uma patrulha alemã visse [...] e as pegassem elas não seriam apenas presas, mas também mortas. E isto era a vida das pessoas. (Entrevista com Vladka Meed, 28 de fevereiro de 2000, Nova York).

Em se tratando especificamente da educação elementar, a população judaica estava cônscia que a educação de crianças em idade inferior a quinze anos, seria uma das áreas que dependeria diretamente de uma resistência civil. Numa situação normal, sem guerra, essas crianças possivelmente estariam em escolas cursando o ensino elementar, mas com o gueto, isso não foi possível de forma legalizada. Assim, em dezembro de 1940, quando falharam as tentativas feitas por Adam Czerniakow para conseguir dos alemães a autorização de reabrir escolas, os professores do gueto começaram a dar cursos elementares clandestinos, na tentativa de substituir a educação elementar que elas receberiam nas escolas.

Os grupos de crianças miseráveis, abandonadas à própria sorte, sem escolarização, vítimas fáceis da imoralidade nas ruas, foram um dos graves problemas sociais nesse gueto. $\mathrm{O}$ momento exigiu que uma atitude social fosse tomada em conjunto com medidas educativas. A

\footnotetext{
2 Oneg Schabat: (em hebraico, "os que festejam o Schabat"). Nome da organização fundada por Emanuel Ringelblum com a finalidade de reunir a documentação do Arquivo do gueto de Varsóvia. RINGELBLUM, 2003, p. 491.
} 
educação deveria velar pela vida física, emocional e, na medida do possível, pela vida intelectual dessas crianças.

Foi preciso esperar até $1^{\circ}$ de outubro 1941 para que as autoridades alemãs autorizassem a abertura de 6 escolas elementares. No fim do único ano escolar autorizado (1941-1942), que foi do outono de 1941 até o verão de 1942, contavam dentro do gueto 19 escolas elementares que agrupavam 6.700 alunos, ou seja, $16 \%$ do conjunto de crianças do gueto em idade de serem alfabetizadas. Apesar disso, a maior parte da atividade educacional clandestina continuou até o fim desse gueto (SAKOWSKA, 2007, p. 19 - 21).

A política de educação alemã na Polônia era parte do esforço global nazista de destruir a intelligentsia (polaca e judaica) nos territórios ocupados, portanto, a educação na Polônia ocupada foi severamente restrita para ambos, poloneses e judeus. No entanto, uma vez que os judeus estavam no gueto, os nazistas demonstraram pouco interesse nas suas atividades políticas e sociais.

Kardos (2002, p. 39) cita um ensaio do Oneg Schabat, intitulado "Estudo Preliminar no Ensino de Pessoas Durante a Guerra", que inclui um relato da política alemã com relação ao ensino durante a ocupação da Polônia. De acordo com o ensaio, os alemães inicialmente consideraram tratar as escolas clandestinas como um desperdício de tempo porque, ironicamente, eles não viram as escolas como uma ameaça ao seu principal interesse primário que era “desmoralizar as massas, a fim de destruir [...] cultura Judaica, que é tão 'perigosa' para a humanidade." Devido a isso, uma forte rede de escolas clandestinas desenvolveram-se.

A importância da educação clandestina na vida da comunidade judaica no gueto de Varsóvia se indica pelas referências às atividades educacionais nos registros produzidos por essa comunidade. Esses registros demonstram que a educação organizada clandestinamente foi um dos mais importantes cenários para a resistência individual e comunitária judaica.

O teórico Nathan Morris (1937, p.xxv) em sua obra, The Jewish School: An Introducion to the History of Jewish Education, ressalta que as conquistas realizadas pela educação judaica não deveriam ser vistas como coisas insignificantes. Para ele, se a educação formal [ou escolar] pode ser descrita como o principal meio pelo qual um povo procura preservar e impulsionar sua vida coletiva, então o trabalho da escola judaica é único. A sobrevivência do judeu em condições de adversidade inigualável embora considerada por alguns um enigma e para outros um milagre é, para o autor, o resultado de um sistema bem sucedido de educação extraordinariamente adequado tanto às necessidades do indivíduo como da comunidade. 
No gueto de Varsóvia, os judeus, degradados da condição humana, buscam, por meio da educação clandestina, fazer frente aos conceitos nazistas, preservando sua dignidade e defendendo sua própria ideologia, vinculada à sua sobrevivência e a sua continuidade como indivíduos e como povo. Tais prioridades deveriam orientar a prática pedagógica dos educadores junto à criança no gueto.

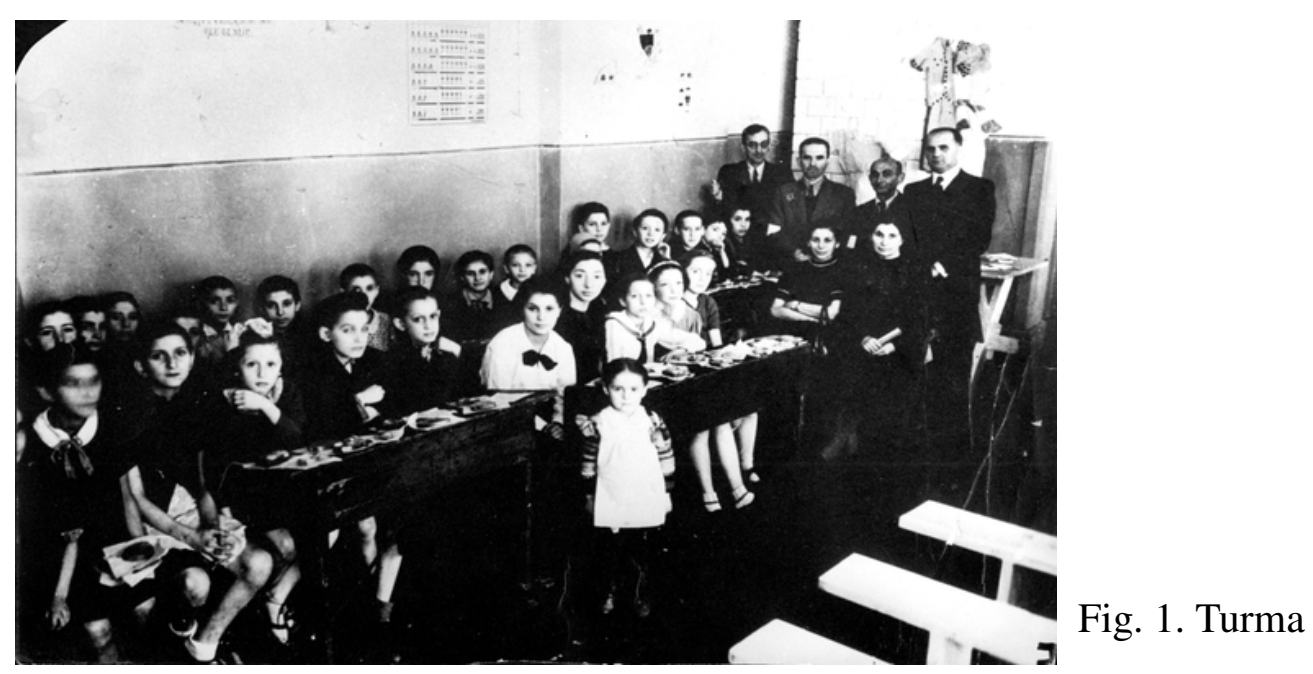

de uma escola clandestina no gueto de Varsóvia, 1940-1941.

Arquivo do Yad Vashem.

De acordo com Sakowska (2007, p. 22) a forma mais escolarizada do ensino clandestino foi assegurada dentro dos imóveis onde se encontravam as cantinas. Essa forma de ensino foi estabelecida pela Comissão de coordenação dos patrocínadores escolares (KPPS). Sob este nome inocente escondiam-se organizações educativas de pré-guerra, afiliadas aos diferentes partidos políticos que representavam o pluralismo das correntes dos pensamentos da sociedade judaica tais como: Tarbut, Shulkult, Agudat Israel, Yavne etc.

A TsYShO foi fundada em Varsóvia em 1921 e recebia seu principal apoio do Bund ${ }^{3}$ e dos Poalei Tzion ${ }^{4}$, de esquerda. Sua instrução era oferecida em iídiche, usando o polonês

3 Bund: Abreviatura de Der algemeiner yidisher arbeiter bund. [União geral dos trabalhadores judeus]. Vem do alemão Bund, "união". Partido socialista de orientação assimilacionista e antisionista, propugnava uma identidade judaica baseada somente nos aspectos culturais, entre eles na língua iídiche. RINGELBLUM, 2003, p. 479.

4 Em hebraico, "os trabalhadores de Sião". Movimento sionista socialista fundado na Rússia sob a inspiração do pensador marxista Ber Borochov (1881-1917). Logo se dividiu em duas tendências. RINGELBLUM, 2003, p. 493. 
apenas para a história e a geografia da Polônia. Suas escolas seguiam um currículo secular de ideologia predominantemente socialista. Seu caráter secular e iidichista eram princípios intocáveis, desde 1925, quando foram proclamados. As 86 escolas catalogadas pelo historiador Baron (1974, p. 195) em 1934-35, educavam 9.936 crianças predominantemente nas áreas anteriormente russas - 45 dessas escolas, com 4.730 alunos estavam concentradas nas províncias de Bialystok e Vilna.

A $T s Y S h O$ teve um papel efetivo na educação de crianças em idade inferior a quinze anos no gueto de Varsóvia. Esta patrocinou, na clandestinidade, cursos administrados em três cantinas-escola sob os cuidados da Centrala Zwiazku Towarzystw Opieki nad Sierotami $i$ Dziecmi Opuszczonymi (Centos) - [Central de Associações de Proteção aos Órfãos e Crianças Judias Abandonadas]. Esses espaços eram usados simultaneamente para alimentar e educar as crianças por meio de um ensino mais próximo ao ensino regular. A da Rua Karmelicka $n^{\circ} 29$ e da Rua Krochmalna ${ }^{\circ} 36$ estava sob a tutela do Bund, e a da Rua Nowolipki $n^{\circ} 68$ sob a tutela do partido Poalei Tzion.

De acordo com Sakowska (2007, p. 22) no seio da organização TsYShO, os partidos dos trabalhadores do Poalei Tzion e do Bund exerciam uma influência maior. Os dois partidos, no entanto, diferenciavam-se sensivelmente quanto ao programa de ensino: contrariamente ao Poalei Tzion, o Bund era hostil à emigração e à luta pela criação do Estado judeu na Palestina. Em compensação, os dois partidos eram favoráveis a uma escola laica utilizando como língua de ensino o iídiche, considerando-a como a língua nacional dos Judeus.

Maria Klepfisz, pedagoga, mãe do chefe de um dos elos da Organização Judia de Combate (ZOB), era a diretora da escola da Rua Karmelicka. A cantina-escola da Rua Nowolipki ${ }^{\circ} 68$ era dirigida por três educadores: Fejga Herclich-Blit, Natan Smolar e Izrael Lichtensztejn. Este último, com a ajuda de seus alunos, encarregou-se de esconder a primeira parte dos documentos coletados por Oneg Schabat.

Nem todos os refeitórios organizaram a educação como foi o caso dessas três cantinasescola. Muitos ofereciam cuidados às crianças durante meio período [meio-dia], por meio de um programa para os necessitados e para os refugiados de toda a Polônia, como foi o caso dos centros também administrados pela Centos. Além disso, havia muitas crianças doentes e desnutridas que não conseguiam participar de um programa de ensino como o oferecido pela TsYShO nessas cantinas-escola. A documentação a seguir é referente aos objetivos e métodos do ensino elaborado pela $T s Y S h O$, com base nas experiências e reflexões de vários 
educadores:

\section{Os Objetivos de Nosso Trabalho}

1. Aspiramos a transformar os pontos de abastecimento em centros de educação e cuidados para as crianças.

2. Preocupamo-nos com prioridade pela saúde da criança, aspiramos mais que tudo a desenvolver nela o sentido necessário de higiene e harmonia.

3. Neste presente tão perigoso, queremos envolver com nossa proteção a vida espiritual da criança.

4. A fim de criar um espaço aberto às influências educativas, esforçamos-nos para transformar o grupo de abastecimento em um coletivo de crianças unidas por um laço recíproco e de interesses comuns.

5. Esforçamo-nos para dar às crianças, nestes pontos, a possibilidade de uma vida afetiva, sobretudo oferecendo-lhes no futuro a maior quantidade possível de experiências felizes.

6. Temos a preocupação de dar uma educação social e moral à criança, cultivando um sentimento de companheirismo, sociabilidade e de responsabilidade, com um enfoque particular na precisão.

7. Aspiramos, na medida do possível, a favorecer o desenvolvimento intelectual da criança.

8. Aspiramos a inculcar nas crianças o amor e o apego pela língua e a cultura iídiche.

\section{Os métodos de trabalho}

Para atingir os objetivos evocados, fazemos nosso trabalho segundo os métodos seguintes.

1. Os grupos devem, na medida do possível, ser homogêneos quanto ao nível intelectual e à idade das crianças.

2. As crianças estão sob a vigilância sanitária e médica permanente dos médicos, responsáveis de higiene e dos educadores.

3. Habituamos as crianças a cuidar delas mesmas, de sua higiene e de sua aparência externa convenientemente.

4. Habituamos as crianças às formas da boa educação, particularmente referente à 
comida.

5. Encorajamos as crianças a ficarem atentas à harmonia e à arrumação de seus aposentos e do lugar em geral - semear flores em potes, decorar as paredes com pinturas, imagens e demais coisas neste gênero. Damos atenção particular ao cultivo de plantas como meio de aproximar as crianças da natureza e como fator de educação harmoniosa.

6. Aspiramos a exercer uma influência sobre a vida da criança em casa, buscando implementar, ali, os bons hábitos adquiridos e mantendo um contato com o lar da criança.

7. Associamos as crianças a todas as tarefas que espera o grupo, criando formas de autogestão [vigilância durante as refeições, vestiários, pias, cuidado dos potes de flores, vigilância da higiene, etc].

8. Em concordância com os preceitos de trabalho enumerados, animamos conversações a respeito de temas como: 1) higiene e a cultura na vida cotidiana; 2) o companheirismo e a aptidão à ajuda mútua; 3) a natureza viva - em relação com o cultivo das plantas e a criação de pequenos animais; 4) e também, ocasionalmente, as festas.

9. Contamos ou lemos histórias adaptadas ou obras literárias, como por exemplo: para os mais jovens, $O$ Métayer, Sete bons anos, Uma questão, Um processo contra o vento, de Peretz; O Canivete, Ao violino, Péssakh desperdiçada, Mathusalem, Motl, o filho do chazan Peyse, de Sholem Aleykhem; Pinocchio, Robinson Crusoe, histórias bíblicas [A venda de Joseph], mitos gregos; para as crianças maiores, Tevi o leiteiro, as Histórias de Kasrilevke, uma página do Cântico dos Cânticos, de Sholem-Aleykhem; Contos populares de Peretz; Kidusch Hashem, Os Vizinhos, de Asch; A cabana do tio Tom, Os Caçadores de micróbios, Os Miseráveis, a epopeia do Tanach.

10. Cantamos canções com as crianças, ensinamos poesias, fazemos teatrinhos de contos e de canções.

11. Organizamos jogos diversos com as crianças (cf. o livro Jogos e Distrações de Gilinski, Grundman e Vafner)

12. Antes das refeições, podemos separar cinco minutos a exercícios físicos.

13. Organizamos, em momentos apropriados, festas e distrações para as crianças. 
(Fim de 1940- Inicio de 1941, gueto de Varsóvia. Programa dos cursos clandestinos sob a tutela do TsYShO implementados nas cantinas-escola da Rua Karmelicka $n^{\circ} 29$, da Rua Krochmalna $n^{\circ} 36$ e da Rua Nowolipki $n^{\circ} 68$. Ring I, $n^{\circ}$ 204. Texto em iídiche datilografado por Oneg Shabat . 2 f., 2 p. 205 x 286 mm. In: SAKOWSKA, 2007, pp. 166 - 169).

A documentação apresentada é citada parcialmente no artigo de $\operatorname{Kardos}$ (2002, p. 53) com o título: "Um esboço das atividades pedagógicas nos pontos de Alimentação na Rua karmelicka, 29, Rua Nowolipki, 39, e Rua krochmalna, 96”, onde ela faz referência às escolas patrocinadas pela $T_{S} Y S h O$ que funcionavam em refeitórios, chamadas nesse estudo de cantinas-escola.

Embora haja divergência quanto ao número da Rua Nowolipki, que segundo documento apresentado por Sakowska (2007) se refere ao número 68, e Kardos (2002) se refira ao número 39, observasse que o documento citado por Kardos oferece uma percepção quanto aos objetivos de três escolas elementares operando em cantinas-escola, onde na sessão "Os objetivos de nosso trabalhos" é apresentado os oitos objetivos abordados neste estudo.

Kardos (2002, p. 53) destaca o primeiro desses oito objetivos onde se diz: "nós fazemos o possível para transformar os pontos de alimentação em centros que tenham sucesso pedagogicamente e influência às crianças”. Tal objetivo aponta para o desejo e a dedicação dos educadores em transformar o refeitório em um ambiente educacional, e de cuidado à criança de modo a reter seu interesse.

Entre os objetivos do programa de ensino, incluíam-se também dar atenção especial à vida espiritual da criança. As atividades educativas visavam principalmente a fazer a criança sentir-se como membro de um grupo com dificuldades iguais as suas; esse sentimento coletivo ajudaria à criança a suportar a situação ameaçadora em que vivia; o trauma, assim, deixava de ser individual, passando a constituir-se em algo que outras crianças de seu grupo também suportavam.

Para resguardar a saúde da criança, tanto em relação a si mesma como em relação aos outros que compartilhavam da mesma experiência, a criança era conscientizada quanto a sua própria higiene, pois apesar de todas as limitações tais como: pouca comida, falta de roupas, sapatos, sabão e água para garantir roupas e corpos limpos, as crianças deveriam manter-se 
limpas na medida do possível. Desenvolver com elas o sentido de higiene livrá-las-ia de enfermidades e epidemias, além de ser uma forma de manterem-se dignas.

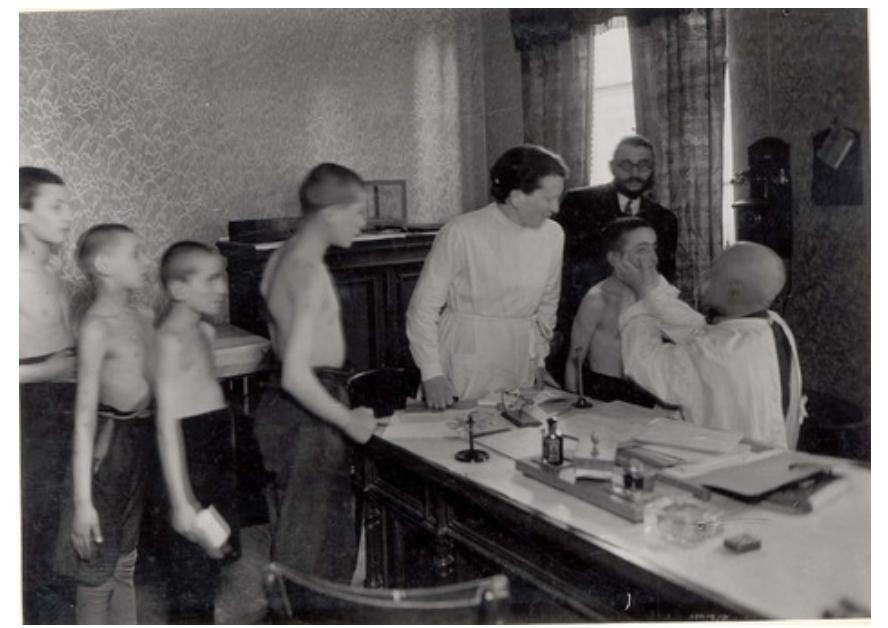

Fig.2. Crianças que recebem um exame médico na Rua Gesia,11, gueto,Varsóvia, Polônia. Arquivo Yad Vashem. Origem: Judenrat, Varsóvia.

No documento "Prestação de contas da Comissão para a autogestão das crianças e redações dos alunos dos cursos clandestinos no local da cantina-escola número 145 da Centos, na rua Nowolipki, 68", um dos alunos dessa escola, Liliensztejn Sala, descreve o medo que algumas crianças sentiam na hora do banho, mas também demonstra o esforço da educadora em conscientizá-las sobre a importância da higiene, transformando a hora do banho em um momento prazeroso:

Um [a] verão [b]. A agitação [c]. Depois do almoço [c] ela nos falou [d] banho. Na sala [e] barulho [e]. Não, ninguém vai tomar banho porque lá cortam-se os cabelos. Eu lamentei que não houvesse banho porque eu gosto muito de me lavar e brincar na água. Nossa professora acabou nos convencendo de que não nos cortariam os cabelos. As crianças ficaram felizes. No dia seguinte, nós fomos tomar banho. Ah! Se vocês tivessem ouvido aqueles risos e aqueles gritos! Nós pulamos na água, jogamos água um no outro e cada um de nós saiu tão limpo que dava prazer em ver. Desde este dia, íamos para o banho sem que nos pedissem, porque nos ensinaram que a higiene, é saúde, e nós guardamos isto. (Depois de primeiro de junho de 1941, gueto de Varsóvia). 
A não participação da criança nas atividades ligadas à higiene implicava em contrair doenças que poderiam levá-las a óbito, e por isso era importante trabalhar a questão com a colaboração e participação da criança. Para evitar as epidemias, muitos educadores priorizavam o ensino de princípios de higiene e responsabilidade, visando a proteger e harmonizar a criança enquanto ser completo, com necessidades físicas e emocionais.

Os educadores tinham entre seus objetivos resguardar a vida emocional da criança, o que ia além da vida física, por isso os educadores deveriam proteger sua infância, possibilitando a ela, na medida do possível, viver uma vida normal. Entre as atividades ligadas a este objetivo as escolas proporcionavam a criança uma vida cultural intensa, com espetáculos e danças, concertos, concursos de corais de crianças. A alusão ao presente e ao futuro no documento indica que embora a situação presente fosse calamitosa, os educadores tinham esperança num futuro melhor para as crianças, para tanto, não poderiam desvincular o presente do futuro, já que as crianças no gueto representavam a continuidade do povo judeu após a guerra.

Havia também uma preocupação em garantir uma educação social e moral à criança, cultivando nela um sentimento de companheirismo, de sociabilidade e de responsabilidade, com um enfoque particular no momento presente, com suas dificuldades e limitações. Observasse que esse objetivo recorre a uma metáfora ligada a natureza. Ao cultivar na criança tais sentimentos, o educador deveria ter paciência e esperar pelo fruto do seu trabalho. A criança do gueto teve o coração endurecido pela situação extrema em que se encontrava, no entanto, com os devidos cuidados sistemáticos dos educadores, esse coração se tornaria "um terreno fértil capaz de produzir belos frutos" (grifo nosso).

Quanto ao desenvolvimento intelectual da criança, embora importante, os educadores entendiam-no como não prioritário. A sobrevivência era o foco principal, apesar de serem ministradas disciplinas tais como geografia, história, matemática e literatura. Tal aspiração deve-se ao fato de que a criança no gueto estava constantemente com toda a sua atenção direcionada à comida. Os educadores, assim como os que trabalhavam nos chamados lares ou nos cantinhos das crianças, estavam cônscios de que para reter a atenção da criança de modo a levá-las a frequentar os espaços escolares constituídos no gueto, como por exemplo, as cantinas-escola, deveriam partir do pressuposto que o interesse primário da criança era o pão. Por isso, era necessário primeiramente providenciar o alimento para depois, promover 
atividades educativas.

Conseguir mudar o foco da criança em tais condições exigia muito dos educadores, e a realidade não permitiu que um programa integral de escola elementar fosse possível. De acordo com Sakowska (2007, p. 23) era impossível cumprir um programa integral de ensino de uma escola elementar. As educadoras abandonaram igualmente as regras de disciplinas, exigindo unicamente a limpeza e a pontualidade dos alunos. Os quarenta e cinco minutos que deveria durar uma aula não podia ser levado em conta, e não havia mais notas ruins, pois elas eram sem interesse pedagógico para as crianças enfraquecidas e apáticas do gueto. Das estimulações positivas, as refeições em particular eram as preferidas, o que encorajava as crianças a lavarem-se e a estudar.

Para tornar as atividades educacionais mais atrativas e desviar a atenção da criança da obsessão pela comida, o desenho, os jogos e as canções ocuparam espaço prioritário no atendimento às crianças. A título de exenplo, tem-se o ensino oferecido na cantina-escola da Rua Nowolipki, 68, onde cursos de desenho foram oferecidos pela pintora Gela Seksztajn, que deixou aquarelas representando as crianças do gueto. Os numerosos concertos, as matinês artísticas e literárias com as crianças eram outra forma de combate pela sobrevivência diária no gueto, permitindo à criança vivenciar experiências felizes mesmo em meio a tragédia.

Quanto à relação da criança com o alimento, essa foi ensinada a manter o equilíbrio frente à comida, como por exemplo, esperar sua vez de comer. O contato com a natureza era estimulado pelo cultivo de plantas e da criação de pequenos animais. A relação da criança com a natureza proporcionava harmonia e as lembravam de que ainda eram humanas, embora a imagem do gueto fosse sombria, sem cor, sem flores, sem esperança de uma nova primavera.

Visando a continuidade do trabalho educativo das cantinas-escola nos lares das crianças, seus educadores buscavam uma educação que perpassasse os "muros das escolas" (grifo nosso), com isso, o que era aprendido durante as aulas deveria ser colocado em prática em família. Assim, a criança além de cuidar de sua higiene pessoal, deveria incentivar sua família a tais práticas.

Identificou-se, ainda, na proposta educacional dessas cantinas-escola a implantação de uma autogestão entre crianças, associando-as a todas as tarefas que estavam designadas aos grupos de crianças separadas por idade e nível de estudo. Com esta prática, as crianças aprendiam a cuidar umas das outras de forma responsável e a não viverem ociosas. Em uma 
redação sem assinatura, encontra-se o relato do trabalho realizado pelas crianças em uma das escolas patrocinada pela $T_{S} Y S h O$. (SAKOWSKA, 2007, p. 99, 100):

[...] Toda espécie de trabalho é realizado pelas crianças, escrevem-se artigos sobre diferentes temas, cantam-se e aprendem-se canções, assim cria-se uma atmosfera de amor pelas crianças. As crianças preparam uma festa em honra da "Semana de limpeza". Encenam, escrevem e leem belas histórias. Realiza-se um trabalho intenso para transformar o refeitório em uma escola de vida comum, feliz e de amor uns pelos outros.

\section{Sem}

\section{assinatura}

Conforme a redação acima, as práticas elencadas faz jus aos objetivos e metodologia do trabalho das escolas patrocinadas pela $T s Y S h O$ no tocante à autogestão. Tais práticas giravam em torno de questões de higiene na vida diária da criança; o companheirismo e a prontidão para a ajuda mútua; a natureza viva e as festas, como foi o caso da festa em honra a Semana da Limpeza, entre outras.

De acordo com Sakowska, (2007, p. 25) os professores tinham que combater a inclinação das crianças à mendicância, protegê-las contra o contrabando ou atividades perigosas e depravantes. Um dos métodos mais eficientes de proteção às crianças foi de associá-las a forma de autogestão. Comissão de crianças assegurava o serviço no refeitório, outras eram encarregadas de organizar espetáculos, de enfeitar as salas com faixas decorativas, de desenhos em cores muito apreciadas dentro do gueto; outras cuidavam das plantas, ou entregavam diplomas para as crianças pela limpeza e boa apresentação. O comitê de autogestão dos alunos era um precioso aliado para os professores na sua luta quotidiano, para manter a união entre eles, a solidariedade e a disciplina nos grupos sempre ameaçados.

Transformar o refeitório em um ambiente escolar, feliz e de amizade era um desafio para os educadores. As crianças deveriam sentir amor pelo ambiente escolar por ela frequentado, por isso havia canções, recitações de poesias, encenações, como ler e contar alguns contos e obras literárias adequadas para a idade da criança. Assim, o lazer, o lúdico e a arte consistiram em formas de respeitar a criança como criança de acordo com o conceito de infância vigente no século XX, quando a criança passa a ser vista como um ser com características próprias, diferentes dos adultos. A criança tem seu tempo, seus desejos, e ideias 
próprias de seu mundo infantil, diferentemente do adulto.

Havia também, por parte dos educadores, um interesse em despertar na criança amor e devoção pela língua e cultura iídiche, apesar de no gueto as organizações educacionais clandestinas terem autonomia para escolher o método de ensino nas suas próprias propostas e na língua escolhida por eles que podia ser dar em iídiche, hebraico e polonês. Nas cantinasescola patrocinada pela $T S Y S h O$, a língua de ensino era o iídiche, já que os educadores defendiam a educação na língua materna das crianças, pois assegurava uma chance de promoção social nas camadas laboriosas de trabalhadores que não tinham os meios de frequentar um Liceu ou a Universidade.

Para tanto, eram oferecidos às crianças, segundo um critério de idade, textos literários de autores clássicos da literatura judaica, tais como: Sholem-Aleykhem, Yitskhok-Leybush Peretz, Abraham Reyzen, Maria Konopnicka, Léon Tolstoï, etc. Embora essas escolas tivessem objetivos múltiplos, grande importância foi dada ao estudo da História, da literatura, e cultura judaica. Autores como Y.L. Peretz e Sholem-Aleykhem conseguiam falar aos corações das crianças.

\section{Considerações}

A análise dos objetivos e métodos de ensino patrocinado pela $T_{s} Y S h O$, aponta para uma proposta educacional voltada para questões de cunho social, emocional e pedagógico sem, no entanto, abrir mão de suas tradições culturais e históricas. Um currículo elaborado de acordo com as prioridades ditadas pela situação extrema que se havia formado em consequência do confinamento e da política nazista.

O programa atentou para a realidade da criança no gueto e para as suas necessidades fundamentais, desse modo, a educação teve como princípio primário garantir a integridade da criança, quanto à preservação de sua vida física e de sua dignidade humana. Garantido essa integridade de maneira sistemática os educadores poderam, na medida do possível, oferecer um ensino mais próximo ao ensino regular.

A proposta curricular da $T S Y S h O$ revela, ainda, como a escola serviu como um caminho por meio do qual os judeus no gueto mantiveram sua história e cultura viva e buscou assegurar seu futuro, incutindo em sua juventude o amor pela língua e a cultura iídiche, sem descuidar de assegurar a dignidade humana das crianças do gueto. Ou seja, considerou o momento presente da criança permitindo que adultos e crianças reagissem à realidade de modo a trasnformá-la, recorreu ao passado histórico fortalecendo na criança sua memória 
histórica e cultural e visualisou um futuro com possibilidades, onde a criança sobrevivente à guerra daria continuidade a sua vida como indiviudo e como povo.

\section{Referências}

\section{Fontes}

GRYNBERG, M. Voces del gueto de Varsovia. Tradução Katarzyna Olszewska Sonnenberg y Sergio Trigán. Barcelona: Alba Editorial,s.1.u, 2004..

RINGELBLUM, E. Crónica del gueto de Varsovia. Tradução, Seleção, introdução e notas de Katarzyna Olszewska Sonnenberg y Sergio Trigán. Barcelona: Alba Editorial., s.l.u., 2003.

\section{Obras citadas}

BARON, S. W. História e Historiografia. São Paulo: Editora Perspectiva S.A, 1974.

KARDOS. S. M. Not Bread alone: clandestine Schooling and resistance in the Warsaw ghetto during the holocaust. Havard Educational Review. Cambridge, v.72, nº 1, 2002, p. 33-66.

LEVI, Primo. É isto o homem. Tradução de Luiz Sérgio Henriques. Rio de Janeiro: Paz e Terra, 1988.

MORRIS, Nathan. The jewish school: an introduction to the history of jewish education. London: Eyre and Spottiswood, 1937. 1937.

SAKOWSKA, Ruta. Archives clandestines du ghetto de Varsovie. [Archives Emanuel Ringelblum]. Les Enfants et L'enseignement Clandestin dans le Ghetto de Varsovie. Tome II. Paris: Fayard / BDIC, 2007.

YAD VASHEM. Um dia no gueto de Varsóvia. Tradução Bracha Freundlich. Jerusalém: Yad Vashem, 1993. 